\title{
The Effect of Psychosocial Support Intervention on Depression in Patients with Dementia and Their Family Caregivers: An Assessor-Blinded Randomized Controlled Trial
}

\author{
Froydis Kristine Bruvik ${ }^{a}$ b Heather G. Allore ${ }^{d}$ Anette Hylen Ranhoff ${ }^{b}, c$ \\ Knut Engedal ${ }^{a}$ \\ ${ }^{a}$ Ageing and Health, Norwegian Centre for Research, Education and Service Development,

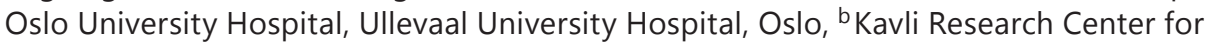 \\ Ageing and Dementia, Haraldsplass Hospital, and ' ${ }^{\mathrm{D}}$ epartment of Clinical Science, \\ University of Bergen, Bergen, Norway; ${ }^{d}$ Department of Internal Medicine, Yale School of \\ Medicine, New Haven, Conn., USA
}

Key Words
Dementia $\cdot$ Caregiver $\cdot$ Psychosocial intervention · Depression $\cdot$ Clinical trial

\section{Abstract}

Background/Aim: A three-component tailored psychosocial 12-month assessor-blinded randomized controlled trial to reduce depression in people with dementia (PWD) and carers was conducted. Methods: A total of 230 home-dwelling dyads of PWD and their carers were randomized to usual care or intervention consisting of three components over 12 months. Primary outcomes were the difference between the baseline and 12-month score on the Cornell Scale of Depression in Dementia (CSDD) in the PWD and on the Geriatric Depression Scale (GDS) in the carers. Results: The intent-to-treat difference between the baseline and 12month change score was not significant between the intervention and control groups for the $\operatorname{CSDD}(p=0.95)$ or GDS ( $p=0.82)$. Conclusions: The trial did not show a significant difference between usual care and the intervention on depressive symptoms in PWD or their family caregivers.

\section{Introduction}

Dementia is a serious and common condition in older adults. It affects their performance and skills in cognitive, practical, and social function [1] as well as mood and quality of life (QoL). The functional losses increase during the course of dementia and lead to dependence 
in functional activities. Even in developed countries where people with dementia (PWD) have access to formal in-home and nursing home care, over the course of the disease, they live most often at home assisted by their family. Caring for a family member with dementia is associated with a high degree of burden and depression as well as social isolation, physical ill-health, and financial hardship for the carers [2]. Several factors are associated with an increased burden in the carers of PWD, such as neuropsychiatric symptoms in the PWD [3], the relationship with the PWD [4-6], and gender [7, 8] and coping skills of the carers [9-11]. Spouses and female carers have been shown to experience the highest burden [7].

The effects of different kinds of psychosocial intervention programs for carers of PWD have been studied. An early meta-analysis by Brodaty et al. [12] reported that psychosocial intervention reduced psychological morbidity in the carers. An intervention including both PWD and carers was found to be most successful [12]. Another review by Pinquard and Sorensen [13] showed significant but weak evidence for an effect of a psychoeducational multicomponent intervention on depression of the carers. This multicomponent intervention involved active participation of the carers [13]. In addition, individually tailored behavioral management therapy and teaching of coping strategies individually or in group settings were reported to improve carers' psychological health [14]. In contrast, education about dementia, group behavioral therapy, and supportive therapy have not been reported to have significant effects on the carers [14]. Group-based support for carers has even been found to have a negative effect on the psychological health of carers, as described in a review by Thompson et al. [15].

A recent review by Corbett et al. [16] on the effect of information about services provided to the PWD and/or the family caregivers reported a positive effect on the QoL and neuropsychological symptoms in the PWD, but not on the burden of their carers [16]. Cooper et al. [17], who studied QoL in PWD, noted that family care coping strategy-based intervention showed improved QoL [17]. However, even if carers with fewer depressive symptoms have less dysfunctional coping [10], a meta-analysis by Li et al. [18] found that interventions to reduce depressive symptoms in carers instead led to increased dysfunctional coping [18].

Brodaty and Arasaratnam [19] reported a reduced burden of carers as well as decreased symptoms of behavioral and psychological symptoms of dementia in a psychosocial intervention trial. This trial was a multicomponent study, tailored to the needs of the PWD and the carers and conducted in 9-12 sessions over 3-6 months [19].

In the past decade, two Scandinavian randomized controlled trials (RCTs) have been conducted, one Norwegian and one Danish study [20-22]. Neither the Norwegian RCT [20], designed as a multicomponent psychosocial intervention trial to reduce the burden in carers and neuropsychological symptoms in the PWD, nor the Danish RCT [22], designed as multicomponent and semi-tailored intervention to reduce depression, reported significant intervention effects. However, the Danish trial demonstrated a small positive effect on depression in the PWD in the unadjusted analysis [22].

Although no Scandinavian RCTs have shown an effect of psychosocial interventions, the literature suggests that individually tailored multicomponent interventions might have beneficial effects and should thus be recommended for PWD and their carers [7, 13, 14, 19, 23, 24]. This paper describes a multicomponent tailored psychosocial intervention trial design to reduce depressive symptoms in PWD and carers.

\section{Methods}

\section{Trial Design}

This is an assessor-blinded multicenter RCT of PWD and their carers. The threecomponent intervention is a 'psychosocial support program' with the control arm receiving 
Table 1. Description of intervention components

a Counseling: During the first 3 months, each family received five individual counseling sessions of $1 \mathrm{~h}$ duration. The session was used to identify needs as well as family resources. A problem-solving method $^{1}$ was used to find new ways of coping with unmet needs. The PWD participated in two of these sessions. One of the sessions was used for the whole family network. The primary carer participated in all five sessions. One local interventionist typically led each session, whereas two interventionists participated if there were several family members at the network meeting.

b Education: The primary carers received education about dementia either in a community-based educational program or in two half-day seminars. They also received a booklet about dementia.

c Group meetings: Six group meetings, each of $2 \mathrm{~h}$ duration, were conducted twice a month. These meetings were organized separately for carers and PWD. In the group meeting of the carers, the main approach was structured problem solving to identify and implement new coping strategies. In the PWD group, every meeting started with education or a conversation about dementia. The other main focus of these meetings was on 'pleasant events'. Two local interventionists conducted the group meetings with 6 PWD or carers. If there were less subjects in the group, 1 principal investigator led the meeting. Two follow-up group meetings, organized as booster sessions, took place after 12 months.

1 Problem-solving method in six steps: (1) Definition of a problem: as concrete as possible. (2) Brainstorming: all proposals to be recorded. (3) Discussing the proposed solutions: pros and cons. (4) Choosing a solution or a combination of solutions. (5) Detailed description of how to carry out the chosen solution. (6) Evaluation at the next meeting.

'treatment as usual' (table 1). The trial was conducted in 17 local authorities in Norway. Local primary social and health-care workers carried out the intervention program. The trial was approved by the Regional Ethics Committee for medical research in eastern Norway and registered at ClinicalTrials.gov in September 2009 (ID No.: NCT0 1287767).

\section{Recruitment of Participants}

The participants were recruited from October 2009 to May 2011. Seventeen local authorities included a median of 12 (IQR 9-14) dyads of PWD and a primary family caregiver for the trial. The minimum of included dyads in 1 authority was 8 after 2 of the authorities were merged. The authorities received a fee for each included dyad, covering the expenses to screen and enroll participants and conduct the intervention. The duration of screening prior to randomization varied by authority and ranged from 2 to 12 months. The participants were recruited in several ways: through letters to memory clinics, at general practitioner offices, at home care offices, at adult day care centers, or through the education program run by the National Dementia Care Association ('Demensforbundet').

\section{Participants}

Sample Size

Prior to the trial, we calculated the sample size for the RCT using Sample Power (SPSS Version 19). Based on the Danish Intervention Study (DAISY) [21], a difference of two points on the Cornell Scale for Depression in Dementia (CSDD) between the two groups would be of clinical significance. With a power of $80 \%$, a two-sided type I error of 0.05 , and an estimated dropout rate of $15 \%$, the trial required 115 dyads in each group to detect a difference of two points on the CSDD between the two groups.

Accordingly, we included 230 dyads of home-dwelling PWD and a principle family caregiver with at least weekly face-to-face contact. The PWD needed to be diagnosed with dementia according to the ICD-10 criteria for research, to have a score of $\geq 15$ on the Mini-Mental 


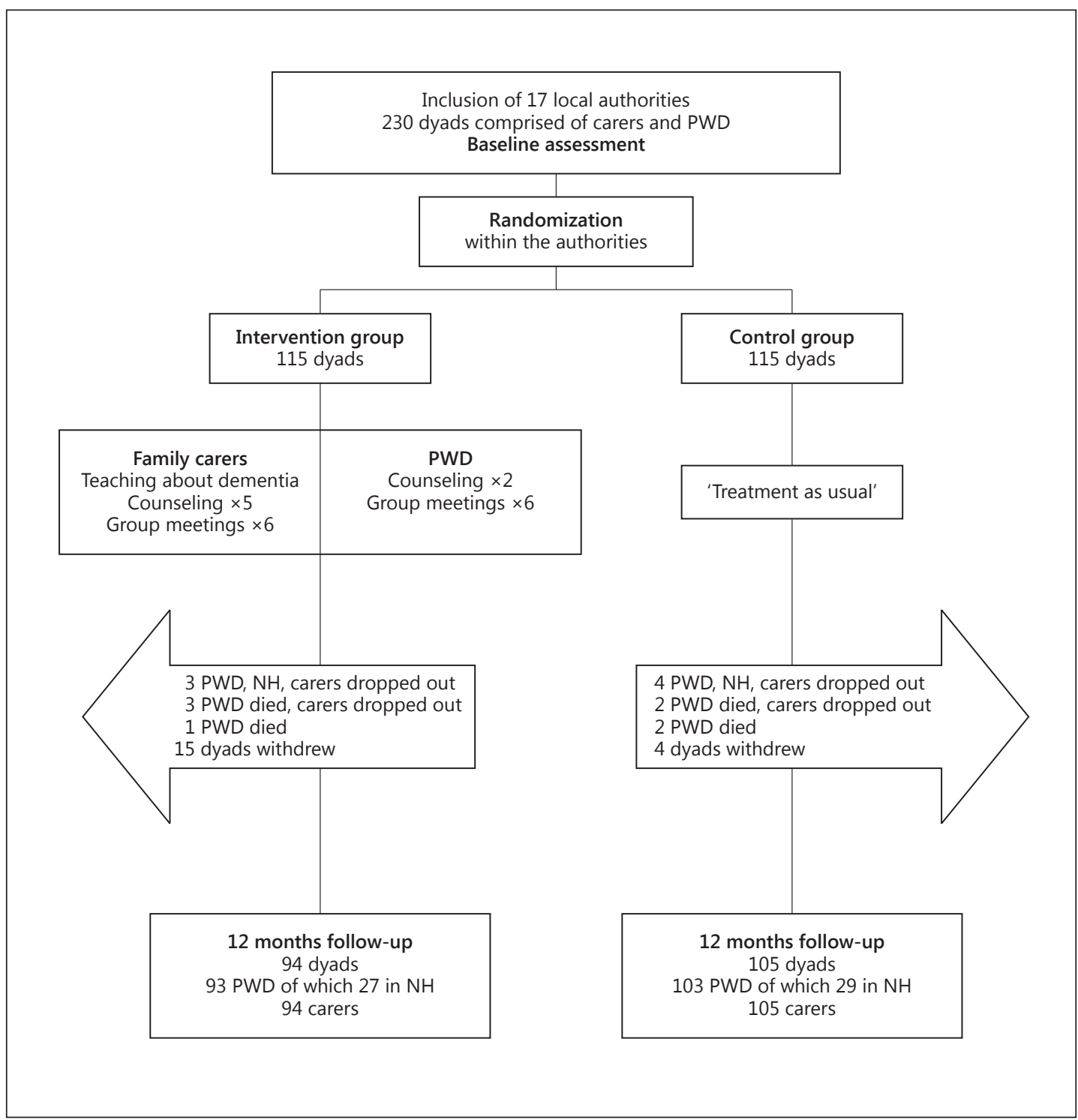

Fig. 1. Flowchart of the study. $\mathrm{NH}=$ Nursing home.

State Examination (MMSE) [25], and to be able to give informed consent to participate in the trial. The carers were required to score at least 5 on the Relatives' Stress Scale (RSS) [26].

Due to the variety of methods used for recruitment, the numbers of potential participants who were contacted and did not meet the inclusion criteria were not tabulated. One PWD was included with the Clinical Dementia Rating (CDR) with a cutoff score of $>1$ [27] instead of the MMSE because of aphasia after stroke.

All 230 included participant dyads provided informed consent and are presented in the flowchart in figure 1. During the 12-month follow-up period, 31 dyads and 3 PWD were lost to follow-up. Nineteen dyads withdrew from the trial and 8 of the PWD died. However, of these 8 dyads, 3 of the carers continued in the trial after the PWD died. Sixty-three PWD moved to nursing homes during the 12-month follow-up period, 56 of these dyads continued in the trial, but 7 dropped out. The CSDD results were missing for 4 of the PWD at baseline 
Bruvik et al:: The Effect of Psychosocial Support Intervention on Depression in PWD and Their Family Caregivers: An Assessor-Blinded RCT

and for 1 PWD at the 12-month follow-up. The Geriatric Depression Scale (GDS) results were missing in 3 of the carers at the 12-month follow-up.

\section{Randomization}

We used a block randomization procedure with blocks of 6 dyads in each authority using a computer program ( $\mathrm{R}$ - version 2.11.1). Thus, half of the dyads in each community were randomized to either the intervention or the control group.

Blinding

Two local interventionists from each local authority included the participants and conducted the baseline assessments in their own local authority. They had no contact with the control group throughout the intervention period and unlike the participants, they were not given further information about the study. At baseline, the assessment was done before the randomization, and at the 12-month follow-up, all assessors were blinded to the dyad's group assignment. The randomization procedure was conducted by a statistician using $\mathrm{R}$ 2.11.1. The follow-up assessments were done by 8 nurses, 3 medical doctors, 1 psychologist, and 1 occupational therapist, who were all blinded to the randomization.

\section{Interventionists}

A total of 32 local interventionists, 28 registered nurses, and 4 occupational therapists were involved in the inclusion, the baseline assessment, and the intervention to the carers. Additionally, 32 assistance interventionists, mostly registered nurses, were involved in the group meeting intervention for the PWD. To reduce bias due to therapist effect, all interventionists were trained in the same seminars, received manuals for every session of the intervention, and registered deviations to the manual during the intervention period. The same interventionist team was used for each dyad in the intervention arms within each authority.

\section{Intervention}

The intervention is described in table 1 and was conducted over 12 months. The carers received all three components of the intervention. Carers who had participated in an education program about dementia prior to the trial could choose if they wanted to participate in the education program again.

The group meetings were organized in parallel for the carers and the PWD. This addressed the needs of the transportation to the meetings and the limitation that some PWD could not stay at home alone. If needed, the local authorities received financial support to cover the costs associated with transportation, facility rental, and refreshments at the group meetings.

The local interventionists participated in 5-day workshops, where they received training in mapping the screening baseline data and carry out the intervention with the 'structured problem solving' therapy. The interventionists were given supervision throughout the trial during regular meetings, workshops, telephone conferences, and seminars. To ensure equality, all interventionists received supervision by the principle investigator (F.K.B.) in group meetings. They also regularly received newsletters and were free to seek ad hoc support as needed from the principal investigator. Manuals were made for each counseling and group meeting.

Control Condition

During the trial, the dyads in the control group were informed about available services in their authority and were free to seek treatment and support in addition to any ongoing care. 


\section{Outcomes}

The primary end points for the PWD and their carers were the changes of depressive symptoms between baseline and the 12-month follow-up. The CSDD [28] was used to measure depression in the PWD. The scale is a proxy-based instrument consisting of 19 items with a score ranging from 0 to 2 on each item (total score between 0 and 38). A higher score indicates more symptoms of depression. A cutoff score of $\geq 8$ was used to indicate depression according to a Norwegian validation trial among PWD [29].

The GDS [30] was used to measure depression in the carers. The scale is translated and adapted to the Norwegian language and culture by one of the authors (K.E.). The GDS is a selfrated 30 -item scale ranging from 0 to 30 with yes $=1$ (symptom present) or no $=0$ (symptom not present). A higher score indicates more symptoms of depression. A cutoff score of $\geq 11$ was used to indicate depression [31]. The scale was originally developed as a self-rating tool for elderly persons and is validated for this population but can most probably also be used for adults as it covers typical symptoms of depression.

\section{Other Assessments of the Carers}

The carers completed the Norwegian version of the RRS [26]. The scale consists of 15 items, which can be scored from 0 (not at all) to 4 (to a high degree) with a total range score from 0 to 60 . A higher score denotes higher burden.

The carers' age, gender, education, occupational status, and kinship with the PWD were recorded. Carers were asked to estimate the time they had used to assist or look after the PWD during a typical day in the preceding month.

Other Assessments of the PWD

Cognitive function was assessed by the MMSE Norwegian Revised version (MMSE-NR) $[25,32]$. The scale consists of 20 items, with a possible score between 0 and 30 . A higher score indicates better cognitive function. The Neuropsychiatric Inventory (NPI-Q) [33-35], a 12 -item scale, was used to assess neuropsychiatric symptoms. In this trial, we used the severity score, which can vary between 0 and 36 . A higher score indicates more severe symptoms. The function in activities of daily living (ADL) was assessed by the Physical SelfMaintenance Scale (PSMS) and the Instrumental Activity of Daily Living (IADL) scale, both developed by Lawton and Brody [36]. The PSMS scale measures basic activities, such as bathing, eating, and using the toilet. It has six items, rated on a 5-point scale, from 1 = 'maintain the activity' to $5=$ 'do not maintain the activity at all/need full assistance'. The minimum score is 6 and the maximum score is 30. A higher score indicates a poorer function. The IADL scale assesses the more complex instrumental ADLs that are required for independent living, such as shopping, cooking, and managing finances. The scale has eight items, and the scoring system is similar as for the PSMS, but the maximum score on each item varies between 3 and 5 , which gives a minimum score of 7 and a maximum of 31 . A higher score indicates a greater need for assistance.

PWD's age, gender, living arrangements and duration of symptoms of dementia were recorded.

\section{Statistics Analysis}

Descriptive statistics of baseline characteristics were generated for continuous and categorical variables by the treatment arm (table 2). Two-tailed unpaired Student's t tests were used to compare the control and intervention groups for continuous measures, whereas $\chi^{2}$ tests were used for categorical data. All analyses were carried out according to the intentionto-treat principle. Separate multilevel linear regression models were run for the primary outcomes, and baseline to 12-month change scores in CSDD and GDS. Then, they were adjusted 
Bruvik et al.: The Effect of Psychosocial Support Intervention on Depression in PWD and Their Family Caregivers: An Assessor-Blinded RCT

Table 2. Characteristics of the 230 carers and 230 PWD at baseline

\begin{tabular}{|c|c|c|c|c|}
\hline & $\begin{array}{l}\text { All } \\
(n=230)\end{array}$ & $\begin{array}{l}\text { Intervention } \\
\text { group }(n=115)\end{array}$ & $\begin{array}{l}\text { Control group } \\
(\mathrm{n}=115)\end{array}$ & $\mathrm{p}^{*}$ \\
\hline \multicolumn{5}{|l|}{ Carer characteristics } \\
\hline GDS & $6.5 \pm 6.1$ & $7.3 \pm 6.5$ & $5.6 \pm 5.5$ & 0.033 \\
\hline GDS $\geq 11$ & $53(23)$ & $33(28.7)$ & $20(17.4)$ & 0.042 \\
\hline Female gender & $177(77)$ & $88(77)$ & $89(77)$ & 0.876 \\
\hline Age & $63.5 \pm 12$ & $64.1 \pm 12.2$ & $62.9 \pm 11.4$ & 0.446 \\
\hline Years of education & $12.7 \pm 3.8^{7}$ & $12.6 \pm 3.9^{5}$ & $12.8 \pm 3.6^{2}$ & 0.233 \\
\hline Employed outside household & $98(43)^{3}$ & $43(38)^{2}$ & $55(48)^{1}$ & 0.121 \\
\hline Living together with the PWD & $128(56)$ & $69(60)$ & $59(51.3)$ & 0.184 \\
\hline Relation to the PWD & & & & 0.688 \\
\hline Spouse & $122(53)$ & $66(57.4)$ & $56(48.7)$ & \\
\hline Children & $92(40)$ & $44(38)$ & $48(42)$ & \\
\hline Other & $16(7)$ & $5(4.4)$ & $11(9.6)$ & \\
\hline Face-to-face contact & & & & 0.514 \\
\hline Daily & $139(60)$ & $74(64.9)$ & $65(56)$ & \\
\hline 4-6 days a week & $14(6)$ & $7(6)$ & $7(6)$ & \\
\hline $2-3$ days a week & $53(23)$ & $22(19.3)$ & $31(27)$ & \\
\hline Once a week & $23(10)$ & $11(9.6)$ & $12(9.5)$ & \\
\hline Hours spent on caring, PADL & $0.9 \pm 2.3^{4}$ & $0.86 \pm 1.8^{2}$ & $0.9 \pm 2.8^{2}$ & 0.914 \\
\hline Hours spent caring, IADL & $2.4 \pm 2.4^{4}$ & $2.7 \pm 2.5^{2}$ & $2.1 \pm 2.3^{2}$ & 0.069 \\
\hline Hours per day spent on preventing/guiding & $1.8 \pm 3.8^{4}$ & $1.8 \pm 3.8^{2}$ & $1.8 \pm 3.8^{2}$ & 0.896 \\
\hline Help from other family members & $102(57)^{52}$ & $43(38)^{30}$ & $55(48)^{22}$ & 0.604 \\
\hline RSS & $23.6 \pm 11.1$ & $24.3 \pm 10.9$ & $23 \pm 11.2$ & 0.361 \\
\hline \multicolumn{5}{|l|}{ PWD characteristics } \\
\hline Cornell score & $8.0 \pm 5.6^{4}$ & $8.1 \pm 5.3^{1}$ & $7.9 \pm 6.0^{3}$ & 0.815 \\
\hline Cornell score $\geq 9$ & $89(39)^{4}$ & $48(42)^{1}$ & $41(37)^{3}$ & 0.398 \\
\hline Female gender & $123(54)$ & $60(52)$ & $63(55)$ & 0.692 \\
\hline Age & $78.4 \pm 7.5$ & $78.3 \pm 7.5$ & $78.5 \pm 7.5$ & 0.860 \\
\hline Years of education & $10.1 \pm 3.4$ & $10.3 \pm 3.6$ & $9.8 \pm 3.3$ & 0.269 \\
\hline Marital status & & & & 0.408 \\
\hline Married & $130(57)$ & $70(61)$ & $60(53)$ & \\
\hline Unmarried & $4(2)$ & $3(2.6)$ & $1(1)$ & \\
\hline Widow or widower & $84(37)$ & $39(34)$ & $45(40)$ & \\
\hline Divorced & $11(5)$ & $3(2.6)$ & $8(7)$ & \\
\hline MMSE score & $21.2 \pm 3.6$ & $20.9 \pm 3.5$ & $21.4 \pm 3.8$ & 0.313 \\
\hline Duration of symptoms, years & $4.4 \pm 29$ & $4.1 \pm 2.9$ & $4.6 \pm 2.9$ & 0.288 \\
\hline PSMS score & $9.6 \pm 3.7$ & $9.9 \pm 4.0$ & $9.3 \pm 3.4$ & 0.176 \\
\hline IADL score & $21.3 \pm 58^{1}$ & $21.7 \pm 5.9^{1}$ & $20.9 \pm 5.7$ & 0.267 \\
\hline NPI severity & $9.5 \pm 6$ & $8.8 \pm 5.6$ & $10.2 \pm 6.4$ & 0.083 \\
\hline
\end{tabular}

Values are means \pm SD or $\mathrm{n}(\%)$. Superscripts indicate the number of missing data.

$* t$ test for continuous variables and $\chi^{2}$ for categorical measures were used.

for the effect of the local authority where the dyads were enrolled; thus, the dyads were nested within the local authority. As each local authority had the same interventionists, this adjustment controls for differences among interventionists, as well as unmeasured differences among the local authorities to which both treatment arms within an authority may be exposed. Therefore, the dyads were nested within each local authority. Each model tested the effect of the intervention on the change of the score between baseline and at 12 months for the CSDD and the GDS after controlling for authority where the dyad was enrolled and baseline score. To address the nesting of dyads within the local authorities, the variance was adjusted 
Bruvik et al.: The Effect of Psychosocial Support Intervention on Depression in PWD and Their Family Caregivers: An Assessor-Blinded RCT

Fig. 2. CSDD with $95 \%$ CI from

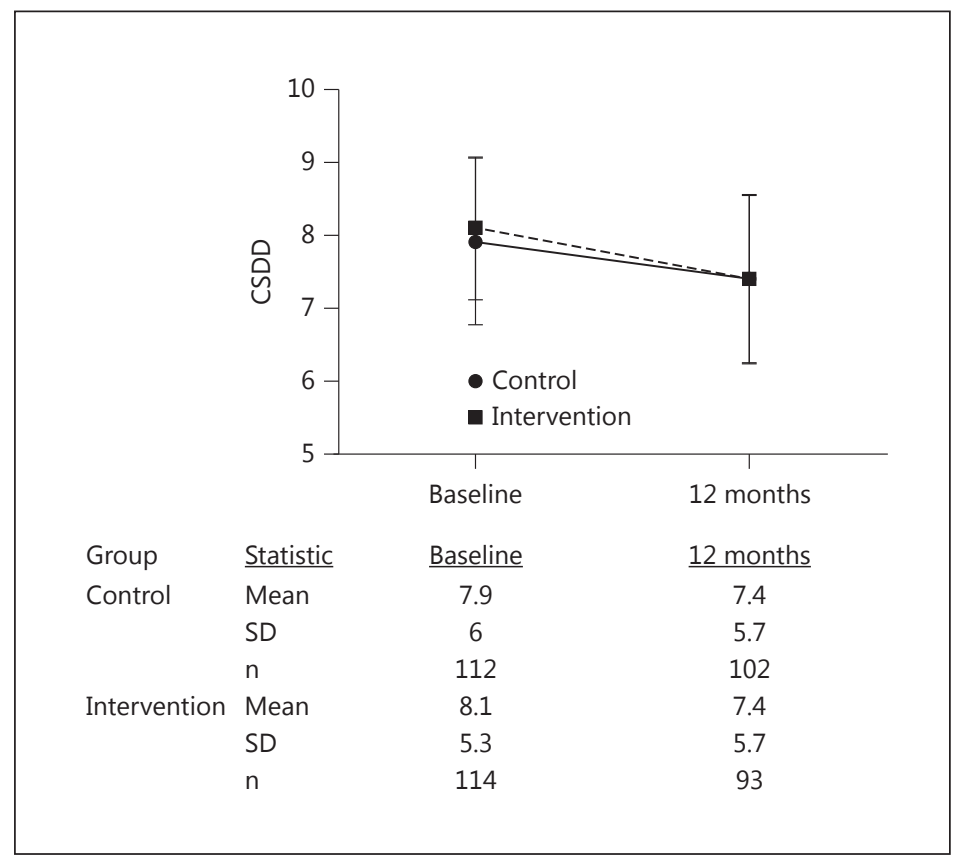

to reflect the nonindependence of dyads. Secondary outcomes, such as being depressed at 12 months (defined as a CSDD $\geq 8$ for PWD and GDS $\geq 11$ for carers), were modeled by separate multilevel logistic models testing for whether there was an intervention effect on baseline depression. These models were similarly controlled for local authority and baseline score, and the variances were adjusted to reflect the nesting of dyads within the local authority.

The control and intervention groups were compared for the number of nursing home admissions, deaths, and loss to follow-up for reasons other than the aforementioned over the course of the trial (12 months) using Fisher's exact test for each outcome. Only individuals who completed CSDD and GDS were included in the final analysis $(n=191$ and $n=195$, respectively). For all models, the goodness-of-fit and residuals were examined. SPSS (IBM SPSS Statistics 19) was used to generate basic comparative statistics. SAS v9.3 (Cary, N.C., USA) was used for model programming.

\section{Results}

The baseline characteristics of the dyads in the intervention and control groups were comparable (table 2), except that symptom load of depression was significantly higher among carers in the intervention group than in the control group [7.3 (SD 6.5) vs. 5.6 (SD 5.5), p = 0.033 ], as were the proportions with GDS $\geq 11$ ( 28.7 vs. $17.4 \%, p=0.042$ ).

The difference between the baseline to 12 -month change score was not significant between the intervention and control groups for the CSDD ( $p=0.9477)$ (fig. 2) or GDS ( $p=$ 0.8236) (fig. 3). Depressive symptoms at baseline, assessed by GDS in carers and by CSDD in the PWD, explained the greatest amount of the variance in their respective outcomes (GDS: $F$ value $=34.44, \mathrm{p}<0.0001 ;$ CSDD: $\mathrm{F}$ value $=80.10, \mathrm{p}<0.0001$ ). However, variance explained by the design variable local authority was nonsignificant for the outcome on the GDS ( $\mathrm{p}=$ 0.4485 ), but explained the variation of the CSDD outcome ( $F$ value $=2.43, p=0.002$ ), albeit it was only approximately one fortieth of the effect of depression at baseline. 
Fig. 3. GDS with $95 \%$ CI from baseline to 12 months.

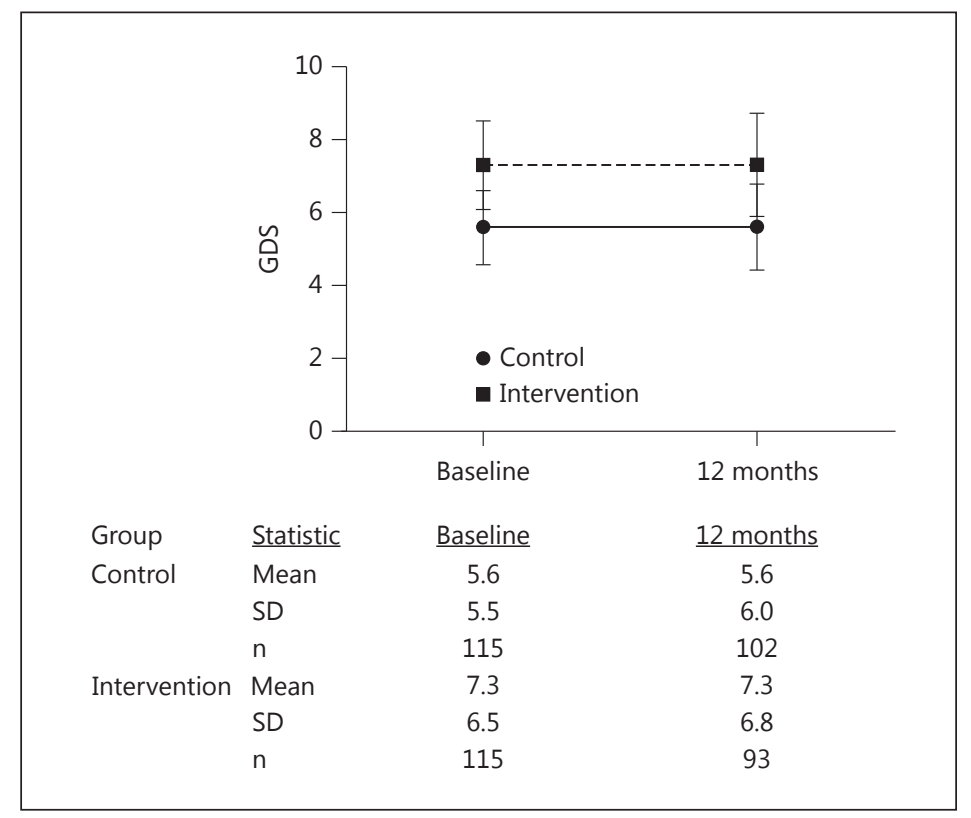

The analysis of whether there was a difference between the intervention and control arms for depression at 12 months in PWD and whether the PWD was depressed at baseline showed no significance $(\mathrm{p}=0.7614)$. Similarly, there was no significant effect on the carers' GDS at 12 months compared to the carers' baseline depression ( $p=0.5461$ ).

No differences were found for nursing home admission (30 intervention PWD and 33 controls; $p=0.657$ ) or deaths ( 5 intervention PWD and 4 controls; $p=0.701$ ) over the 12 -month trial period. However, there was a significant difference in withdrawals from the trial, 15 from the intervention group and 4 from the control group $(\mathrm{p}=0.015)$. There were no significant differences in baseline depression symptoms among survivors without 12-month outcomes (withdrawn or moved to a nursing home without follow-up) and those with 12-month outcomes [GDS: diff = 0.33 (SD 6.14), $p=0.70$; CSDD: diff = 1.98 (SD 5.66), $\mathrm{p}=0.0961$ ].

\section{Discussion}

\section{Main Findings}

We found no significant differences between the intervention group and the control group with respect to change in the two primary outcomes, depressive symptoms in the PWD and the carers (on the CSDD and the GDS), as measured between baseline and the 12-month follow-up. This trial was based on available knowledge of useful intervention strategies, included a sufficient number of PWD and carers and was conducted in line with the recently successful factors for psychosocial intervention described in the literature [7, 17, 19, 23, 24]. The lack of an intervention effect may have several explanations.

Although the sample size was estimated using findings from DAISY [21], we could not a priori know the local authority effects of this multisite intervention. The imbalances between the intervention and control group at baseline (table 1) could hardly have influenced the results, as the two groups did not show within-group change in the carer GDS score at followup. Although the symptom load of depression in the carers (GDS) was significantly higher in the intervention group than in the control group at baseline, this difference was adjust- 
ed for by the statistical analysis and therefore could not explain the lack of a significant effect of the intervention. Being a spouse, particularly a wife, or being a daughter carer is known to be associated with increased symptoms of depression [7]. From an earlier publication, using the baseline data of this trial [37], 'living together' was also associated with a decreased QoL in carers. In the present study, there were no significant differences in gender, relationship or 'living together' in the arms, and therefore this does not explain the lack of intervention effect.

The design factor of the local authority in which the dyads were nested had substantial variability for CSDD, which was accounted for in the analytic model. The intervention was carried out by interventionists in 17 different authorities, located in the eastern, southern, western and mid-northern regions of Norway. The design factor of the authority accounted for the interventionists who provided the intervention to all dyads within an authority, unmeasured differences in size, economy, and organization of the available services to support families with a dementia patient that the control dyads may have used.

A possible negative effect of conducting group meetings has been pointed out by the review of Thompson et al. [15] and may partially explain the nonsignificant intervention effect. However, Thompson et al. [15] referred to an intervention informing and supporting carers, while the intervention presented here involved active participation in the group meetings to target needs and find ways to cope with the situation $[17,19]$. Changing ways of coping is difficult to achieve according to a meta-analysis by Li et al. [18], who reported decreased depressive symptoms leading to increased dysfunctional coping. The aim of the present trial was not to change the carers' way of coping in general, but that carers themselves should discover new ways of acting in a difficult situation in their life. However, we cannot deny that the findings of Li et al. [18] may have played a role in the present trial, given the complexity of life with dementia in the dyads of PWD and their carers [4]. Problemfocused coping was a key factor in the present study. Our lack of intervention effect may be explained by the finding pointed out in a review by Li et al. [10] who reported no correlation between problem-focused coping and psychological morbidity in carers.

In the present trial, $76 \%$ of the carers and $61 \%$ of the PWD did not have symptoms of depression at baseline according to the published cutoff levels [29, 31]. Possibly this was a limitation given that the outcome showed a change in GDS and CSDD. However, there was no significant difference between the control and intervention groups showing whether the individual met this depression threshold at baseline. The presence of depressive symptoms at baseline appeared to be the most important factor for depressive symptoms at the 12-month follow-up and indicates the need of focusing on PWD and carers with depression in future research.

The present trial has some limitations. It did not analyze how the information of available services provided to the control group was used. Based on earlier studies [16], we assumed that the use of these services was of limited importance. Another limitation was the use of the GDS for measuring depressive symptoms in carers. The GDS was developed for measuring symptoms of depression in the elderly [38], while the carers in this study had a mean age of 63 years (SD 12). Choosing a scale that is sensitive to the outcome measure is questionable, and this limitation in measuring depressive symptoms in the carers may have had an impact on our findings.

\section{Conclusion}

We did not find that a structured, multicomponent and tailored psychosocial intervention program significantly reduced depressive symptoms in PWD or their family caregivers compared to usual care. Depressive symptoms at baseline were the strongest factor to change in depressive symptoms between baseline and at 12 months, indicating that future investigations should target on this group. 
Bruvik et al.: The Effect of Psychosocial Support Intervention on Depression in PWD and Their Family Caregivers: An Assessor-Blinded RCT

\section{Acknowledgments}

This study was funded by The Research Council of Norway, the Centre for Dementia Research, Aging and Health, the National Dementia Care Association ('Demensforbundet'), the Kavli Research Centre for Aging and Dementia, and the Civitan Norway. The analysis of the trial was conducted at the Yale Claude D. Pepper Older Americans Independence Center (NIH/NIA grant No. P30AG21342).

\section{Disclosure Statement}

F.K.B. has given lectures of this trial at meetings sponsored by the pharmaceutical industry. The authors have no other conflicts of interest to disclose.

\section{References}

1 Engedal K, Brækhus A, Haugen PK: Demens: fakta og utfordringer: en lærebok, ed 5. Tønsberg, Aldring og helse, 2009.

-2 Pinquart M, Sörensen S: Differences between caregivers and noncaregivers in psychological health and physical health: a meta-analysis. Psychol Aging 2003;18:250-267.

-3 Black W, Almeida OP: A systematic review of the association between the Behavioral and Psychological Symptoms of Dementia and burden of care. Int Psychogeriatr 2004;16:295-315.

4 Monin JK, Schulz R, Kershaw TS: Caregiving spouses' attachment orientations and the physical and psychological health of individuals with Alzheimer's disease. Aging Ment Health 2013;17:508-516.

5 Joling KJ, van Hout HP, Schellevis FG, van der Horst HE, Scheltens P, Knol DL, van Marwijk HW: Incidence of depression and anxiety in the spouses of patients with dementia: a naturalistic cohort study of recorded morbidity with a 6-year follow-up. Am J Geriatr Psychiatry 2010;18:146-153.

6 Shim B, Barroso J, Davis LL: A comparative qualitative analysis of stories of spousal caregivers of people with dementia: negative, ambivalent, and positive experiences. Int J Nurs Stud 2012;49:220-229.

7 Etters L, Goodall D, Harrison BE: Caregiver burden among dementia patient caregivers: a review of the literature. J Am Acad Nurse Pract 2008;20:423-428.

-8 Pöysti MM, Laakkonen ML, Strandberg T, Savikko N, Tilvis RS, Eloniemi-Sulkava U, Pitkala KH: Gender differences in dementia spousal caregiving. Int J Alzheimers Dis 2012;2012:162960.

-9 Bruvik FK, Ulstein ID, Ranhoff AH, Engedal K: The effect of coping on the burden in family carers of persons with dementia. Aging Ment Health 2013, E-pub ahead of print.

10 Li R, Cooper C, Bradley J, Shulman A, Livingston G: Coping strategies and psychological morbidity in family carers of people with dementia: a systematic review and meta-analysis. J Affect Disord 2012;139:1-11.

11 Kneebone II, Martin PR: Coping and caregivers of people with dementia. Br J Health Psychol 2003;8:1-17.

12 Brodaty H, Green A, Koschera A: Meta-analysis of psychosocial interventions for caregivers of people with dementia. J Am Geriatr Soc 2003;51:657-664.

13 Pinquart M, Sorensen S: Helping caregivers of persons with dementia: which interventions work and how large are their effects? Int Psychogeriatr 2006;18:577-595.

14 Selwood A, Johnston K, Katona C, Lyketsos C, Livingston G: Systematic review of the effect of psychological interventions on family caregivers of people with dementia. J Affect Disord 2007;101:75-89.

15 Thompson CA, Spilsbury K, Hall J, Birks Y, Barnes C, Adamson J: Systematic review of information and support interventions for caregivers of people with dementia. BMC Geriatr 2007; 7:18.

16 Corbett A, Stevens J, Aarsland D, Day S, Moniz-Cook E, Woods R, Brooker D, Ballard C: Systematic review of services providing information and/or advice to people with dementia and/or their caregivers. Int J Geriatr Psychiatry 2012;27:628-636.

17 Cooper C, Mukadam N, Katona C, Lyketsos CG, Ames D, Rabins P, Engedal K, de Mendonca Lima C, Blazer D, Teri L, Brodaty H, Livingston G, World Federation of Biological Psychiatry - Old Age Taskforce: Systematic review of the effectiveness of non-pharmacological interventions to improve quality of life of people with dementia. Int Psychogeriatr 2012;24:856-870.

18 Li R, Cooper C, Austin A, Livingston G: Do changes in coping style explain the effectiveness of interventions for psychological morbidity in family carers of people with dementia? A systematic review and meta-analysis. Int Psychogeriatr 2013;25:204-214.

19 Brodaty H,Arasaratnam C: Meta-analysis of nonpharmacological interventions for neuropsychiatric symptoms of dementia. Am J Psychiatry 2012;169:946-953. 
20 Ulstein ID, Sandvik L, Wyller TB, Engedal K: A one-year randomized controlled psychosocial intervention study among family carers of dementia patients - effects on patients and carers. Dement Geriatr Cogn Disord 2007;24:469-475.

21 Waldemar G, Waldorff FB, Buss DV, Eckermann A, Keiding N, Rishøj S, Siersma V, Sørensen J, Sørensen LV, Vogel A: The Danish Alzheimer intervention study: rationale, study design and baseline characteristics of the cohort. Neuroepidemiology 2011;36:52-61.

22 Waldorff FB, Buss DV, Eckermann A, Rasmussen MLH, Keiding N, Rishøj S, Siersma V, Sørensen J, Sørensen LV, Vogel A, Waldemar G: Efficacy of psychosocial intervention in patients with mild Alzheimer's disease: the multicentre, rater blinded, randomised Danish Alzheimer Intervention Study (DAISY). BMJ 2012;345:e4693.

23 Olazarán J, Reisberg B, Clare L, Cruz I, Peña-Casanova J, Del Ser T, Woods B, Beck C, Auer S, Lai C, Spector A, Fazio S, Bond J, Kivipelto M, Brodaty H, Rojo JM, Collins H, Teri L, Mittelman M, Orrell M, Feldman HH, Muñiz R: Nonpharmacological therapies in Alzheimer's disease: a systematic review of efficacy. Dement Geriatr Cogn Disord 2010;30:161-178.

-24 Beinart N, Weinman J, Wade D, Brady R: Caregiver burden and psychoeducational interventions in Alzheimer's disease: a review. Dement Geriatr Cogn Disord Extra 2012;2:638-648.

-25 Folstein MF, Folstein SE, McHugh PR: 'Mini-mental state'. A practical method for grading the cognitive state of patients for the clinician. J Psychiatr Res 1975;12:189-198.

26 Greene J, Smith R, Gardiner M, Timbury G: Measuring behavioural disturbance of elderly demented patients in the community and its effects on relatives: a factor analytic study. Age Ageing 1982;11:121-126.

27 Morris JC: The Clinical Dementia Rating (CDR): current version and scoring rules. Neurology 1993;43:24122414.

28 Alexopoulos GS, Abrams RC, Young RC, Shamoian CA: Cornell Scale for Depression in Dementia. Biol Psychiatry 1988;23:271-284.

29 Barca ML, Engedal K, Selbæk G: A reliability and validity study of the Cornell Scale among elderly inpatients, using various clinical criteria. Dement Geriatr Cogn Disord 2010;29:438-447.

-30 Yesavage JA, Brink TL, Rose TL, Lum O, Huang V, Adey M, Leirer VO: Development and validation of a geriatric depression screening scale: a preliminary report. J Psychiatr Res 1982;17:37-49.

-31 Dennis M, Kadri A, Coffey J: Depression in older people in the general hospital: a systematic review of screening instruments. Age Ageing 2012;41:148-154.

-32 Engedal K, Haugen P, Gilje K, Laake P: Efficacy of short mental tests in the detection of mental impairment in old age. Compr Gerontol A 1988;2:87-93.

33 Cummings J, Mega M, Gray K, Rosenberg-Thompson S, Carusi D, Gornbein J: The Neuropsychiatric Inventory: comprehensive assessment of psychopathology in dementia. Neurology 1994;44:2308-2314.

34 Kaufer DI, Cummings JL, Christine D, Bray T, Castellon S, Masterman D, MacMillan A, Ketchel P, DeKosky ST: Assessing the impact of neuropsychiatric symptoms in Alzheimer's disease: the Neuropsychiatric Inventory Caregiver Distress Scale. J Am Geriatr Soc 1998;46:210-215.

-35 Kaufer DI, Cummings JL, Ketchel P, Smith V, MacMillan A, Shelley T, Lopez OL, DeKosky ST: Validation of the NPI-Q, a brief clinical form of the Neuropsychiatric Inventory. J Neuropsychiatry Clin Neurosci 2000;12:233239.

-36 Lawton M, Brody E: Assessment of older people: self-maintaining and instrumental activities of daily living. Gerontologist 1969;9:179-186.

37 Bruvik FK, Ulstein ID, Ranhoff AH, Engedal K: The quality of life of people with dementia and their family carers. Dement Geriatr Cogn Disord 2012;34:7-14.

-38 Yesavage J: Geriatric Depression Scale. Psychopharmacol Bull 1988;24:709-711. 